\title{
Mulemba
}

Revista Angolana de Ciências Sociais

6 (11) | 2016

Políticas, direitos e práticas da sociedade e do Estado

\section{Alguns elementos históricos sobre a actualidade das relações franco-africanas analisadas na obra Contencioso histórico franco-africano de Daniel Yagnye Tom}

\section{Boubacar Namory Keita}

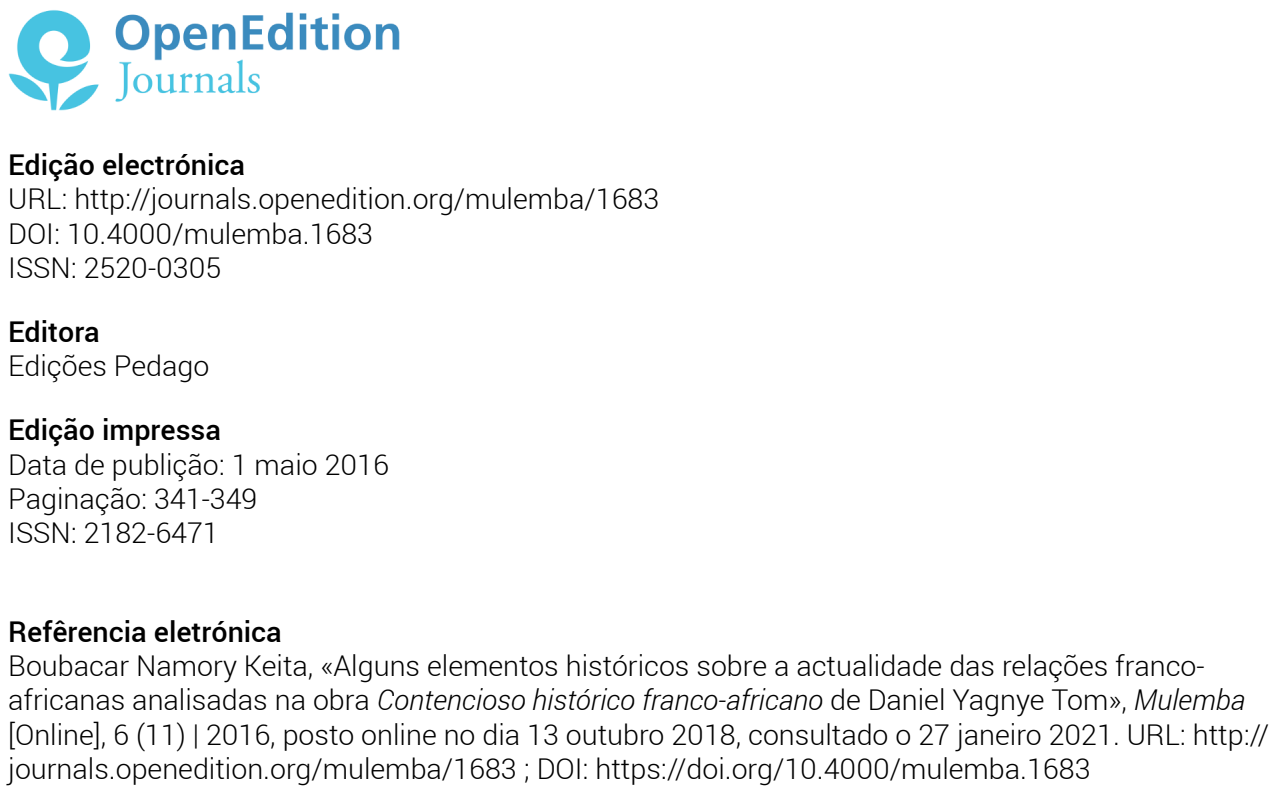

Tous droits réservés 


\section{Alguns elementos históricos sobre a actualidade das relações franco-afri- canas analisadas na obra Contencioso histórico franco-africano de Daniel Yagnye Tom*}

\section{Boubacar Keita**}

O final do século XIX e início do xx foi marcado por uma viragem radical nas relações entre a África e a Europa. Após a famosa e polémica - quanto à sua avaliação - conferência de Berlim (Novembro de 1884-Fevereiro de 1885), os seus resultados vão ensombrar o continente através de um dos episódios mais negros da sua história, a colonização. De facto, depois do prelúdio do tráfico de escravos, o continente conhecerá uma vez mais a interrupção de sua dinâmica endógena, com a perturbação profunda das estruturas sociais, económicas e políticas das sociedades e a imposição de um modus vivendi e de um modus faciendi exógenos. $\mathrm{O}$ mais grave será que as consequências desta perturbação vão se fazer sentir na longa duração,

* Texto de apresentação pública da obra de Daniel Yagnye Tom, O contencioso histórico franco-africano: Os casos dos Camarões, RCA, Togo, Gabão e Chade (Prefácios de Boubacar Namory Keita e Miguel Domingos Bembe. Tradução de Juliano Mabibi e Daniel Yagnie Tom. Luanda, Mayamba Editora, 2016, 112p. [«Biblioteca da História»]), que teve lugar o Anfiteatro principal da Faculdade de Ciências Sociais (FCS) da Universidade Agostinho Neto (UAN), no dia 28 de Março de 2016, no âmbito das suas actividades académicas pela abertura do Ano Lectivo de 2016.

** Historiador, Professor Titular, Chefe do Departamento de História e membro do Conselho Científico-Pedagógico da FCS-UAN. 
tendo comprometido seriamente as perspectivas sonhadas e esperadas, e, consequentemente, as actuais relações entre um conjunto de países africanos e a França.

A colonização, as lutas pelas independências, as soberanias reencontradas, os desafios pós-independentistas de desenvolvimento, os laços relacionais entre uma Europa ontem colonialista e uma periferia, sobretudo africana, com novas entidades políticas independentes, constituídas a partir das décadas de 50 e 60 do século xx, desde muito cedo e continuando ainda pelos dias de hoje, permanecem como temas cruciais, estruturantes, abordados e debatidos por historiadores, politólogos, especialistas das relações internacionais, juristas e sociológos. A razão disto é deveras simples. Em primeiro lugar, os sistemas coloniais elaborados e instalados em África, a fim de melhor explorar, reestruturou aqui e desestruturou ali instituições que vinham sendo pensadas e organizadas ao longo de séculos. Em segunda instância, os novos estados herdaram fronteiras e quadros de gestão territorial e económico-financeiras inadequados para um desenvolvimento sustentável que se pretendia endógeno. Finalmente e, em consequência de tudo isso, a situação actual não augura nada de realmente positivo em termos de perspectivas de construção de nações viáveis, isto é, sólidas, coesas e com estados democráticos de direito - única garantia de bem-estar efectivo de povos.

Hoje em dia, observa-se que há todo um continente que está a braços com problemas estruturais sérios, impeditivos de uma descolagem económica, devido, precisamente, ao seu passado recente de colonizado, que se sucedeu aos longos séculos de escravização, não tendo deixado praticamente tempo para uma eventual resiliência ou recuperação. A colonização - relativamente efémera, de cerca de 50 anos em média - foi um fenómeno e um acto violento de negação e perturbação dos fundamentos identitários de sociedades vítimas. Se a identidade de um povo reside ou é construída na longa duração (história), através das suas actividades de todo o género (cultura), e, se tudo for enraizado e compenetrado nas consciências (psicologia), há de se convir que os actos inscritos nos sistemas e doutrinas coloniais eram de natureza a perturbar seriamente e a destruir iremediavelmente esse substracto. Aqui reside efectivamente os «fundamentos identitários» de povos sem os quais não existe entidade/ comunidade populacional viável. ${ }^{1}$ Entenda-se, trata-se de todo um

1 A propósito deste conceito, que simultaneamente constitui realidade determinante na caracterização dos povos, recomendo a leitura de algumas das mais 
património enraizado que desapereceu: histórico, cultural, religioso e psicológico, de saberes e de saber-fazer acumulados ao longo de milénios, em suma, trata-se de todo o seu referencial estruturante. A negação e a perturbação destes factos equivale a dizer, praticamente, que estamos perante um autêntico genocídio que, pelo menos, debilitou e tornou aviltados esses povos e comunidades.

O Tribunal Penal Internacional (TPI) deveria, justamente por isso, pronunciar uma acusação de «crime contra a humanidade» à França (bem como às restantes ex-potências colonizadoras) porque violou intencionalmente, e em conhecimento de causa, alguns dos preceitos essenciais da vida e dos direitos humanos e dos povos. A essas premissas e conclusão chegaram alguns doutos e esclarecidos investigadores, estudiosos e até políticos africanos acerca do passado colonial que uma parte da África partilhou com a França.

É que, após mais de cinco décadas passadas desde o fim do sistema colonial e de lutas por uma verdadeira «emancipação» e por um enquadramento efectivo no mundo, um lote importante de intelectuais africanos ainda continua a se questionar acerca das razões pela qual o arranque para o desenvolvimento de todo o continente tarda a acontecer.

Em poucas palavras, para o analista camaronês Daniel Yagnye, um dos elementos essenciais de resposta está naquilo que este denominou por Contencioso histórico franco-africano, e que considera, de facto, a raiz do mal camaronês (YAGNYE 2016: 57), mal esse que pode ser extensivo a todos os outros territórios/países colonizados pela França. A ocupação e a exploração dos países africanos pelas potências coloniais gerou um dos mais vivos, duradouros e complexos contenciosos históricos. Hoje, como ontem, o problema persiste de modo activo em que se observa uma França, ex-potência colonizadora e os Camarões, como ex-país colonizado, não importando se com Ahmadou Ahidjo ou se com Paul Biha.

Qualquer historiador, investigador de Ciências Políticas ou das Relações Internacionais ou ainda de Direito Internacional, entende perfeitamente em que consiste este contencioso, em que se baseia e quais causas da sua não resolução até esta data. Nesta sua obra que

importantes reflexões do historiador e cientista social senegalês Cheikh Anta Diop, nas obras seguintes: Antériorité des civilisations nègres. Mythe ou vérité historique? (Paris, Présence Africaine, 1967); Civilisation ou barbarie. Anthropologie sans complaisance (Paris, Présence Africaine, 1981). 
temos o grato prazer de apresentar publicamente, Daniel Yagnye analisa e descreve de forma magistral essa relação dolorosa entre a França e os Camarões. E a sua análise é efectuada sob todos os pontos de vista, seja ele histórico, jurídico, ou psicológico.

Para entender o sentido deste contencioso histórico, o estudioso camaronês esclarece: «[...] O contencioso histórico [...] refere-se a todos os litígios de natureza política, jurídica e propriamente histórica, que opõem a França aos Camaroneses [podendo este] ser resolvido em Tribunal, assim como todas as regras e [outros] procedimentos particulares de Direito aplicáveis a estes litígios. Deste ponto de vista, os nascidos num período remoto devem ser considerados como podendo ainda hoje ser objectos de processos jurídicos». Comparando os actos cometidos pela França durante a ocupação colonial com actos de genocídio, Yagnye vai mais longe quando judiciosamente observa: "É aqui que a categoria de genocídio [o negrito é nosso] apresenta particular interesse, uma vez que os crimes qualificados de genocídio são, enquanto crimes contra a humanidade, imprescritíveis por natureza e escapam à exigência que as leis prevêem para os crimes de Direito comum, que têm o efeito de impedir qualquer acção legal depois de passado o prazo fixado para tal» (YAGNYE 2016: 57-58).

Esta extensa citação tem o mérito de expôr com clareza uma matéria que, regra geral, só aparece em trabalhos cujo domínio é o Direito e que, diga-se de passagem, não é uma ciência e uma técnica de fácil entendimento. Embora este escrito e a sua tónica assentem mais para os Camarões, no entanto, é de concordar com o seu autor, que se trata sobretudo de um «contencioso franco-africano», isto é, isto é, que pode e deve abranger todas as ex-colónias francesas: do Senegal ao Benin, dos Camarões ao Congo Brazzaville, da Argélia, Niger e Chade até a Guiné Conacri e a República Centro-Africana. Todos esses territórios/países foram vítimas dos mesmos «crimes» descritos pelo autor (Ibidem: 58-59).

Em geral, a radiografia de combate dos povos da África, desde 1944 com a primeira grande desilusão provocada pelo silêncio francês na Conferência francesa e africana de Brazzaville até a década de 1970 (!) é edificadora da seriedade e da complexidade do assunto global relativo à colonização. Tal como o é a luta dos nacionalistas do continente, através de movimentos em luta contra a colonização, tal como, demonstrado historicamente, o foi a União das Populações dos Camarões (UPC), um dos mais sérios movimentos da 
luta anti-colonialista e dos mais engajados pela libertação da África do século xx. É emocionante recordar figuras dirigentes dessa luta como o foram Ruben Um Nyobè, Félix Moumié, Ernest Ouandié, Ossendé Afana, porquanto, marcaram os espíritos de uma África invadida, humilhada e a espera de uma "contra-ofensiva» endógena consequente.

Efectivamente, o combate da África contra a ocupação colonial europeia começa com os protestos face, por exemplo, a atitude despreciativa de uma França, que se queria nova depois da ocupação humilhante do seu solo pela Alemanha hitleriana. Com efeito, para os africanos, não foi compreensível a arrogância do novo líder, o jovem dirigente nacionalista General Charles de Gaulle e dos seus companheiros, que se dirigiram a África (Brazzaville) com o objectivo de fazer renascer a França patriótica face a divisão do seu território pelas autoridades alemãs. O problema é que vieram falar da imperiosa necessidade de combater a ocupação imperialista da Alemanha e do renascimento nacional num território também agredido e espoliado por eles e que gostaria de ser consultado, ouvido e respeitado o seu direito à liberdade, à emancipação e ao renascimento. Houve um silêncio grandiloquente dos organizadores do conclave francês de Brazzaville, facto que mostrou e demonstrou que a França e a África tinham noções diametralmente opostas no concernente ao direito de dispôr de si próprias. A partir de Brazzaville, a capital da «África Equatorial Francesa» em 1944, começa, com efeito, o desentendimento entre os dois polos, que continua $\mathrm{e}$ se prolonga até hoje.

Entretanto, em 1946 pareceu ter surgido um outro fôlego para o nacionalismo africano, com a criação do Rassemblement Democratique Africain, isto é, Reagrupamento Democrático Africano (RDA), em Bamako (no então Sudão Francês). Com efeito, a frente anti-colonial prometia novos e salutares desenvolvimentos, com a transformação (consentida voluntariamente pelos principais líderes) dos partidos políticos dos outros territórios de ocupação francesa em «Secções» do RDA. Pela primeira vez a consciência nacionalista no continente atingiu uma maturidade a ponto de constituir uma frente transterritorial pela emancipação e pela independência. A UPC constituia um dos elementos desta nova dinâmica. Nos anos que se seguiram, a França da grande Revolução e dos Direitos Universais, respondeu a esse posicionamento com uma repressão de grande envergadura assente em quatro pontos: 1) do ponto de vista político-jurídico com, 
por exemplo, a instituição em 1954 da chamada Lei Quadro, ${ }^{2}$ que irá «balkanizar» ${ }^{\mathbf{3}}$ aquelas pretensões e a criação da Union Française, que o Referendo de 1958 pretendeu introduzir; 2) socio-cultural, conjuntamente com o «Regime de Indigenato»; 3) económico, com o advento do «Trabalho forçado» e o levantamento do «Imposto de capitação»; e 4) militar, pelo aumento e reforço da capacidade das tropas coloniais através do recurso aos indígenas e dos múltiplos elementos provenientes de colónias asiáticas (Indochina), etc, etc. Esta repressão prolongou-se até ao início da década de 1970 (mesmo após as independências políticas).

Será neste periodo, por exemplo, que a África ficou chocada ao viver - doze anos depois da independência do Ghana e do referendum francês do mesmo ano, e sete anos depois da instituição da Organização da Unidade Africana (ouA) - a feroz repressão, ainda levada a cabo pelas tropas de ocupação francesa, que culminou com o bárbaro assassinato do carismático líder da UPC, Um Nyobè, em 1958. A UPC - recorde-se uma vez mais - a semelhança da Frente de Libertação Nacional da Argélia (FLNA), no Norte do continente, carregava uma nova esperança. Foi precisamente por isso que a França de Charles De Gaulle prosseguiu com a sua estratégia de eliminação física, com uma ferocidade raramente vista na História, dos nacionalistas através de todo o continente, particularmente nos Camarões: Felix Moumié, que tinha substituído Um Nyobè, foi envenenado em 1960; Ossendé Afan, assassinado em 1966 e a ocorrência do fuzilamento público de Ernest Ouandié em 1971. O que em tudo isto se mostrou mais chocante foi o silêncio da Comunidade Internacional (é verdade que sob o efeito ideológico anestesiante da guerra-fria!), assim como a própria Organização da Unidade Africana (ouA).

Concordamos plenamente com Daniel Yagnye quando este chama à responsabilidade toda a intelectualidade contemporânea africana, e sobretudo, os líderes políticos do continente, que apoiaram e ajudaram a metrópole francesa a difundir informações enganosas segundo as quais esses homens, esses lutadores pelas causas por uma indendência efectiva, teriam morrido em lutas fratricidas ou inter-tribais.

A FrançÁfrica continua a incomodar, imiscuindo-se permanentemente - como que naturalmente - nos assuntos internos dos estados da África dita francófona. É uma ideologia, uma prática

2 Mais conhecida por Lei Defferre/Boigny de 1954.

3 Termo criado e consagrado pelo então poeta, escritor e dirigente político da negritude, o senegalês Léopold Sedar Senghor. 
política e económica, uma diplomacia, enfim uma «atitude» neo-colonial própria da França. Pensada e iniciada por Charles De Gaulle, a FrançÁfrica ${ }^{4}$ é a expressão viva e a alimentadora permanente do contencioso histórico da África para com a França. Continuando de pé, no coração das relações dela com a África, até hoje o contencioso histórico não pode ser saldado tão cedo, sobretudo quando todos os sucessivos governos franceses, desde 1966 (quer tanto de esquerda quanto de direita) se reclamam do chamado «Gaullismo». Trata-se uma forma de estar próprio dos franceses (ou nacional) no mundo e, em especial, na África e que transformou todos os partidos políticos (excepto o Comunista) num bloco opaco da social-democracia a geometria variável no concernente à política social interna e às relações com a África. É nosso entendimento que o Gaullismo parece ser a expressão fiel da hipocrisia francesa nas relações desse país com o mundo. Ele impregna toda a sua política global de «cooperação» cultural (Francofonia), económica e financeira (a Caixa de Cooperação), militar (através dos Acordos com o mesmo nome) com as ex-colónias. Face a tudo isso, a África dita francófona tem dificuldade de sair da esclerose político-ideológica para enfrentar as tarefas do verdadeiro desenvolvimento dos países que a compõem. Regra geral, as lideranças políticas sobretudo africanas - por comodismo, colaboracionismo, receio e necessidade, participação consciente e por conveniência - ficaram presas desde os anos 1970, depois de uma série de procedimentos: Assassinatos, golpes-de-Estado dirigidos, corrupção, apoio à oposição reaccionária, economias sob tutela (do Banco Central francês), chantagens relativas à segurança pública, etc. As raras tentativas de quebrar este cerco foram ferozmente abafadas (assassinato de Thomas Sankara em 1987, afastamento compulsivo de Laurent Gbagbo em 2010, ou ainda, a eliminação de Mouamar Khadafi). Ao analisar este percurso complexo, não se pode deixar de não admitir a «dupla parternidade» do contencioso histórico franco-africano, isto é, não reconhecer que se tal só foi possível foi porque houve, e ainda há hoje, Chefes de Estados e líderes africanos que apoiaram a política de genocídio da França, ${ }^{5}$ questões claramente abordadas e bem evidenciadas pelo autor (YAGNYE 2016: 69-80).

4 O chamado Gaullismo é, na realidade, a base ideológica da FrançÁfrica.

5 Alguns aspectos interessantes deste playdoyer são apresentados e analisados por Axelle Kabou na sua obra Et si l'Afrique refusait le développement? (Paris, L'Harmattan, 1991). O leitor interessado poderá compulsar a tradução portuguesa desta obra efectuada pelas Edições Mulemba/Edições Pedago, na colecção «Reler África», dirigida pelo sociólogo Víctor Kajibanga. 
Por tudo isso, o plaidoyer de Daniel Yagnye revela-se pertinente e de actualidade. Se o nacionalismo contemporâneo francês (ou a «doutrina» de gestão global em França) não pode ser compreendido sem o pensamento político de Charles De Gaulle, do mesmo modo, parece-nos impossível entender e avaliar correctamente os ressentimentos e as dificuldades actuais dos povos da África francófona, sem que nos referiramos à colonização, onde residem as raízes, do já tornado crónico, contencioso histórico franco-africano. Consequenteente, afigura-se-nos extremamente importante, e até inadiável, estudar, analisar, debater e difundir todos os elementos que contribuíram para a instalação deste «conflito» histórico com ramificações no presente, a fim de participar na consolidação da consciência histórica em África, único referencial para o advento da plenitude cultural da África Negra (Diop 1981).

Entendemos assim, que a Faculdade de Ciências Sociais (FCS) da Universidade Agostinho Neto (UAN) através desta cerimónia singela, coloca nas mãos do público académico, professores e studantes, e de maneira geral, uma pequena obra - pelo número de páginas - extremamente densa e rica em conteúdo, que aborda, toca e procura sensibilizar precisamente sobre um complexo leque de temas e debates que sempre estiveram e ainda estão em destaque na historiografia africana. Com a sua iniciativa e, consequente com esta abordagem fria e directa, Daniel Yagnie Tom contribuiu certamente para o advento de uma nova era entre ex-colonizadores e ex-colonizados. A História promove e consolida o nosso dever de memória. Obriganos a um esforço permanente de reconciliação, a fim de evitar que se instale ou que ressurjam velhos conflitos geopolíticos, que tendam a prejudicar ou a hipotecar a paz e estabilidade das comunidades e países. «Como se pode promover a paz mundial e a compreensão entre os povos, prevenir os riscos de possíveis conflitos ou a repetição da história, sem esclarecer os diferendos, denunciar os preconceitos $e$ 348 as anomalias nascidas de uma história trágica, cujas repercussões são constatáveis, não apenas em instituições contemporâneas, mas até mesmo nos comportamentos e nas atitudes dos mais altos responsáveis políticos?» (YAGNYE 2016: 38). Em nosso modesto entender, é de facto a ausência de tal esforço que torna possível a actual situação dramática do mundo, que, quotidianamente, continuamos a observar. 


\section{Boubacar Keita}

Historiador, é Professor Titular, Chefe do Departamento de História e membro do Conselho Científico-Pedagógico da Faculdade de Ciências Sociais (FCS) da Universidade Agostinho Neto (UAN). Coordena a «Série História» dos Cadernos de Ciências Sociais. Doutor em Ciências Históricas pela Faculdade de História da Universidade de Estado de Leninegrado (Rússia), lecciona as cadeiras de História de África, de Antropologia Cultural, de Eco-Antropologia e Diversidade Cultural, Etnografia comparada e de Antropologia Física. Além de artigos publicados em revistas especializadas, nacionais e estrangeiras, publicou as obras seguintes: Cheik Anta Diop. Contribuição endógena para a escrita da história africana (Luanda, Nzila, 2009); História da África Negra. Síntese da história política e civilizações (Luanda, Texto Editora, 2009).

[Email: boublik.keita047@gmail.com] 